Faculdade de Ciências Econômicas UFRGS
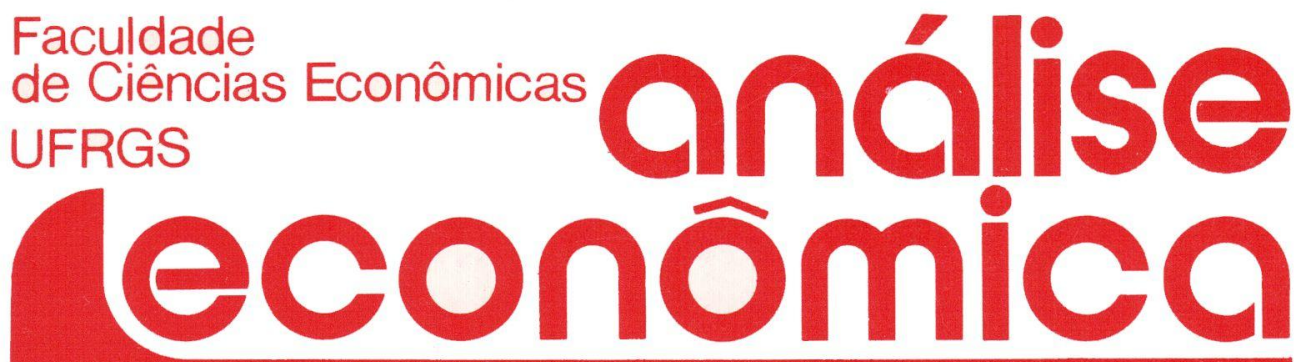

nesta edição:

- POLIITICA SALARIAL:

Roberto Camps Moraes

- DIVIDA EXTERNA:

Yeda Rorato Crusius

-- MECANISMO DAS

RETIFICACCÖES ORÇAMENTÁRIAS:

Manoel Marques Leite

- CREDITO RURAL: Zung Che Yee

- INDL'STRIA E CRISE ATUAL: Claudio F. Accurso
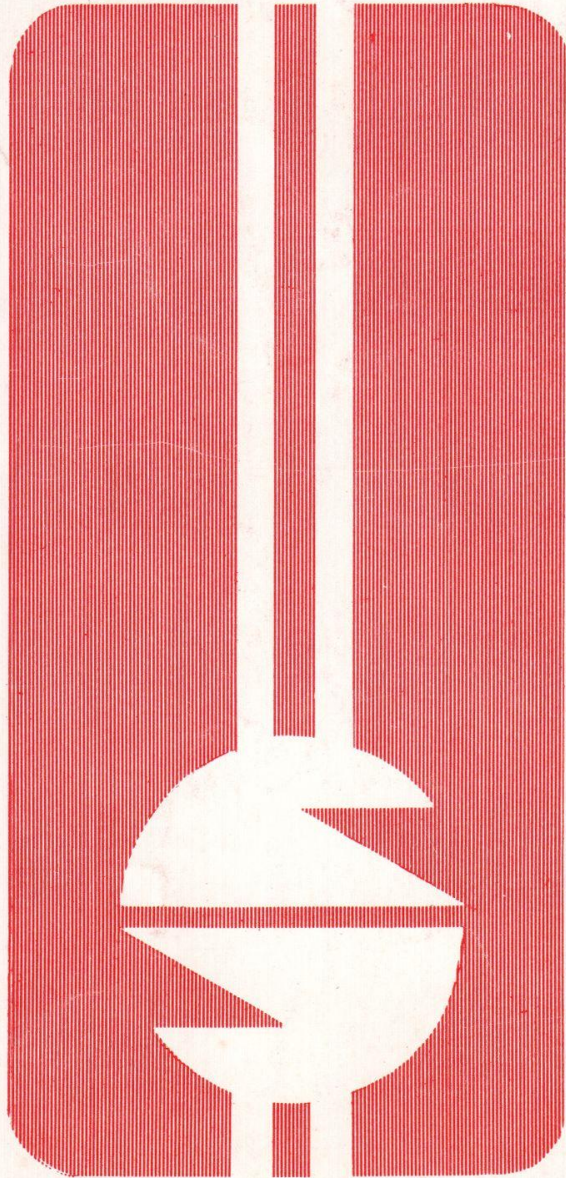

anv 1 
DIRETOR DA FACULDADE DE CIÊNCIAS ECONÓMICAS:

Prof. Antônio Carlos Santos Rosa

VICE-DIRETOR: Prof. Nelson Rokembach

CHEFE DO DEPARTAMENTO DE CIÉNCIAS ECONÔMICAS:

Prof. Renato Batista Masina

CONSELHO EDITORIAL: Prof. Pedro Cezar Dutra Fonseca (Presidente)

Prof. Achyles Barcelos da Costa

Prof. Carlos Augusto Crusius

Prof. Claudio Francisco Accurso

Prof. Edgar Augusto Lanzer

Prof. Ernani Hickmann

Prof. Nali de Jesus de Souza

Prof. Nuno Renan L. de Figueiredo Pinto

Profa Otilia Beatriz Kroeff Carrion

Prof. Roberto Camps Moraes

Profa Yeda Rorato Crusius

ANÁLISE ECONÓMICA é uma publicação semestral da Faculdade de Ciências Econômicas da Universidade Federal do Rio Grande do Sul, visando divulgar estudos e pesquisas de seu corpo docente e discente na área de Economia. Aceitam-se, entretanto, artigos e resenhas bibliográficas de economistas e técnicos não vinculados à Instituição. As matérias assinadas são de responsabilidade exclusiva dos autores. E permitida a reprodução: parcial para fins didáticos.

Toda a correspondência, material para publicação, assinaturas e permutas devem ser dị̣igidas a:

Prof. PEDRO CEZAR DUTRA FONSECA

Revista Análise Econômica

Avenida João Pessoa, $52-3$ ? andar

90.000 - Porto Alegre (RS) - Brasil

Esta edição é uma cortesia do grupo

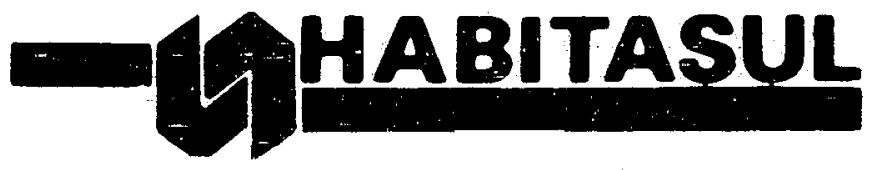




\section{INDÚSTRIA E CRISE ATUAL *}

Cláudio F. Accurso

\subsection{Crise e sua Periodicidade}

O conceito técrico de "crise" se traduz como sendo o ponto de inflexão na etapa ascendente do ciclo, quando a tendência de expansão é rompida e inaugurada uma fase com características contrárias. De maneira corrente também se o toma como um periodo de recessão, onde os níveis do Produto e do Emprego se reduzem paulatinamiente ou permanecem baixos em relação ao ponto de inflexão referido. " Tomado como "ponto" ou como "período", a crise expressa sempre uma situação anômala, porque além de romper uma situação de prosperidade até então desfrutada oferece sempre um quadro de penúria e dificuldades para as grandes maiorias.

Se a crise pode ser tomada como uma situação anormal, sobretudo erigincio-se certos períodos para a observação, adquire absoluta normalidade quando se alargam os horizontes de referência. A periodicidade e a recorrência cíclica são uma constante em qualquer economia capitalista, sendo essa a forma típica e inecessária pela qual o processo de acumulação tem lugar. São essas recorrência e periodicidade que Ihe garantem o "status" de normalidade e a colocam no rol dos fenômenos submetidos a leis e, por isso, suscetíveis de tratamento científico.

O Brasil é bastante familiarizado com as crises, por que não só as experimentou de formas bastante variadas como encontrou saídas para as

* Professor do Departamento de Ciências Econômicas da UTRGS.

Palestra proferida, em 07.06.82, na Sociedade de Economia, no "Seminário Sobre Atualidade Econômica", promovido por essa Sociedade e a Faculdade de Ciências Económicas, da UFRGS.

(1) Gottfried Haberler, "Prosperidad y Depresion". Fondo de Cultura Economica, Mexico, 1953, p. 256. 
mesmas nem sempre consagradas pela ortodoxia do pensamento econômico. Tomando-se o Produto Industrial para base empírica, tem-se os seguintes periodos de desaceleração e taxas negativas de crescimento (Vide Tabela 1):

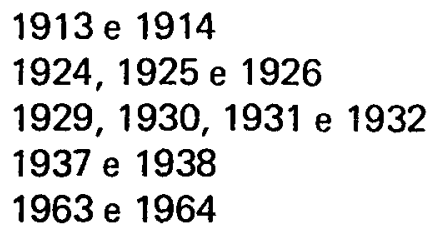

Além dos períodos arrolados, a indústria brasileira conheceu taxas negativas em alguns anos isolados e forte desaceleração em outros, sem que o fenômeno abarcasse mais tempo ou desencadeasse um movimento reversivo demorado. Os anos 1908, 1918, 1921 e 1940 são de taxas negativas e os 1942, 1947, 1967 e 1977, da desaceleração bem acentuada.

A própria experiência brasileira mostra que um ano de quebra no movimento ascendente pode não envolver uma crise e que das crises já observadas prevalecem as de dois anos de recessão sobre as de três.

Os últimos doze anos compreendidos entre 1968 e 1980 são de uma dinâmica impressionante, com o período 1968.73 registrando a taxa média de 13,6, taxa que cai no restante do periodo, porém para o ainda al to patamar dos $7,6 \%$ a.a.. Por isso não deixa de causar espanto o fato de que a taxa de 7,9 em 1980 se despenque para - 9,3, em 1981. ${ }^{1}$ Essa é a única taxa negativa nos últimos quarenta anos e só superada nos últimos oitenta anos pela dos anns de 1914 e 1930

A pergunta que se coloca de imediato é se o quadro se apresenta como algo passageiro, como um "mau ano" e não passa, como tantas vezes ocorrido, de apenas urn episódio passageiro na trajetória nacional. Há um visível desejo de que a recessão seja meteórica, sendo as inúmeras manifestações da esfera oficial como de muitos empresários e técnicos, quando afirmam que "chegou-se ao fundo do poço", uma patente atitude otimista a respeito.

Infelizmente, é sempre imprecisa a determinação do fim do auge ou da depressão, pois só depois de transcorrido algum tempo é que as características de um e outro se definem. Como ensina Stanley Bober, "podemos estabelecer a data de uma depressão só depois que começam a atuar certas forças

(1) Estimativas posteriores situam o ano de $1981 \mathrm{em}-5,4$. 
expansivas definidas, ou comprovar que houve um período de auge quando já começou a contração"'1 .

A força do desejo comum de que o mal seja breve também conspira para uma atitude mais crítica sobre os fatos, na esperança de que não ocorrendo um clima de rompimento das espectativas tanto se evita a propagação de efeitos deletérios como se assimila melhor os que já estão em pleno curso.

O ano de 1982 entrou sob grande incógnita e os resultados do primeiro semestre uma vez mais dividem as opiniões. O próprio ano de 1981 ainda não foi totalmente absorvido, porque não foi pequena a perplexidade que deixou na coletividade nacional. Por isso parece conveniente repassar alguns indicadores como base para reflexões posteriores.

\subsection{Indicadores Gerais}

\subsubsection{Produto Industrial}

Para 1981, os indicadores industriais de conjuntura da FIBGE indicam uma queda na Indústria em Geral de - 9,3 e, na Indústria de Transfor. mação, de $-9,6 .^{2}$, embora novas estimativas do mês de maio indiquem uma taxa de $-5,4$ para a Indústria em Geral, retificação que também se estende ao Produto Nacional que de $-3,5$ passa para - 1,9. ${ }^{3}$ A própria FIBGE admitia para os últimos doze meses, incluindo janeiro de 1982, um crescimento negativo de 9,6 e de 11,0 , respectivamente para o Indice Geral da Indústria e para o da Indústria de Transformação ${ }^{4}$. (Gráfico 1 ).

Independente do quantitativc em questão, todos apontam para uma taxa negativa, ou seja, para uma retração do níve! do Produto para patamares menores do que os atingidos anteriormente. Se verdadeira a taxa de $-9,3$ se estaria em fins de 1981 ao nível do ano de 1979; se válida a taxa de - 5,4, o nível do Produto em dezembro se situaria no primeiro semestre de 1980.

\subsubsection{Empirego}

A queda no emprego industrial foi de 7,1 , sendo de 7,4 na Indústria de Transformação. É interessante observar que o nível de absorção da mãode-obra na Indústria de Transformação foi positivo mas decrescente no pri-

(1) "Los Ciclos y el crecimiento económico" "Amorrortu Editores, Buenos Aires, 1971, p. 44.

(2) FGV "Conjuntura Econômica", fevereiro, 1982, p. 84.

(3) FGV, "Conjuntura Econômica", maio, 1982, p. 13.

(4) Fundc 㳊o do IBGE, "Indicadores Conjunturais da Indústria", 1981/82. 
meiro semestre de 1981, começando com 3,9\% em janeiro para chegar a $0,7 \%$ em junho, o que significa dizer que todo o retrocesso se fez cair no segundo semestre.

Quando se compara essa queda do emprego com o aumento da força de trabalho urbano, de cerca de 4,0\% a.a., tem-se o quadro de desemprego geral do país.

\section{GRAFICO 1 - INDICADORES DA PRODUÇAO INDUSTRIAL - BRASIL BASE FIXA \\ (BASE: MEDIA DE $1975=100$ ) \\ INDICADOR GERAL}

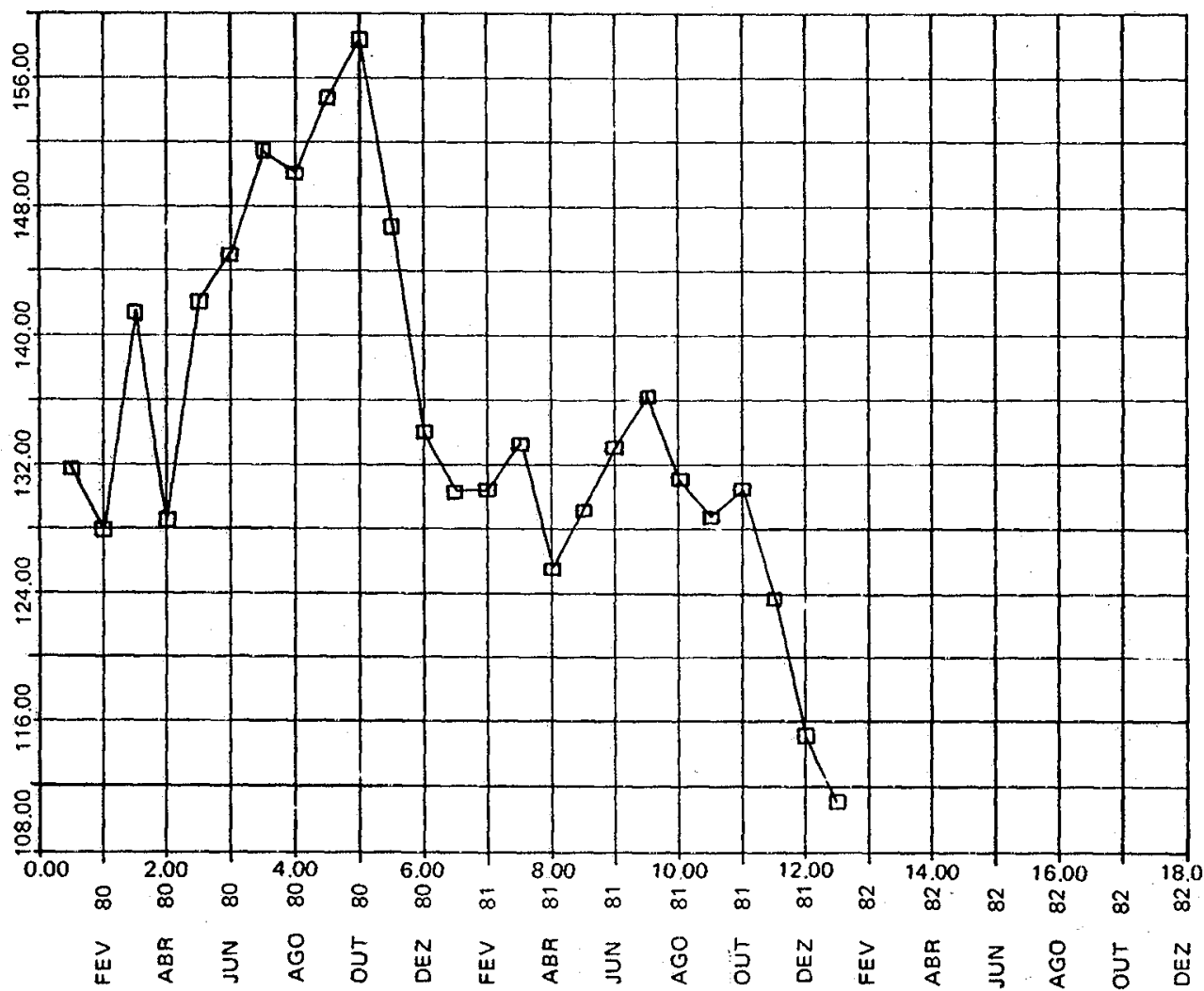

EXECUÇĀO: IBGE/DT/SUEC

FONTE: FUNDACĀO IBGE 


\subsubsection{Consumo de Energia}

O consumo de energia elétrica caiu em $5,1 \%$ no setor industrial, sendo que especificamente na Indústria de Transformação a redução ficou em $5 \%^{1}$. A sua natureza de insumo básico difundido constitui um elemento sólido para a verificação de um menor nivel de ocupação da capacidade instalada. A taxa de $5 \%$ inclusive se aproxima da apontada em maio para a redução do Produto.

\subsection{Efeitos a Nível de Gêneros Industriais}

As reduções assinaladas anteriormente configuram um fenômeno generalizado ou estão confinadas em alguns gêneros, como se enunciava oficialmente no início do fenômeno? Com as únicas exceções dos gêneros "Farmacêutico", "Perfumaria, sabões e velas" e "Fumo", todos os demais apresentam taxas negativas em 1981. ${ }^{2}$

Observando-se os últimos doze meses que incluem janeiro de 1982 , tem-se que as maiores quedas do Produto Industrial se situam nos gêneros abaixo, cujo conjunto perfaz $60 \%$ da Indústria de Transformação:

$\begin{array}{lc} & \frac{\%}{18,9} \\ \text { metalúrgica } & 23,4 \\ \text { mecânica } & 17,9 \\ \text { material de transporte } & 24,0 \\ \text { material elétrico } & 10,2 \\ \text { química } & \end{array}$

$\mathrm{O}$ ano de 1982, janeirc, se inicia com queda em todos gêneros sem exceção, obtendo-se o seguinte resultado de seu agrupamento segundo o uso, comparado com janeiro de 1981:

\begin{tabular}{lr} 
& $\%$ \\
\cline { 2 - 2 } bens de capital & 20,7 \\
bens intermediários & 11,9 \\
bens de consumo & 6,4 \\
bens durável & 28,5 \\
bens não durável & 2,6
\end{tabular}

(1) Fundação do IBGE, ibidem

(2) F.G.V., "Conjuntura Econōmica", fevereiro, 1982, p.84 
Mesmo os ramos ou gêneros ligados ao consumo de massa - bens salários - apresentam queda sensível, sobretudo se a ela for acrescentado o efeito - demográfico.

\subsection{Efeitos a Nível de Espaço Nacional}

As previsões de que a crise se circunscrevia no centro mais dinâmico - a cidade de São Paulo e o $A B C$-- tão pouco se confirmaram. Sabe-se agora que ela atingiu praticamente todo o território, embora se conheçam bolsões muito especiais de exceção.

Em março deste ano, as taxas de desemprego divulgados pela FIBGE eram:

\section{Cidade}

Rio de Janeiro

São Paulo

Belo Horizonte

Porto Alegre

Salvador

Recife

Média
7,3

6,9

7,5

4,9

6,0

7,5

6,7
Area Metropolitana

8,9

8,1

9,0

6,2

7,5

9,1

8,3

o que parece confirmar o caráter geral do fenômeno.

\subsection{Situação da Conjuntura Atual}

Especula-se sobre a reversibiiidade do quadro de 1981, na constatação de sintomas de uma recuperação ou pelo menos de uma paralização das taxas negativas. Em recente artigo na Conjuntura Econômica (abril, p.95-98), o Econ. Claudio Contador, através de um modelo econométrico envolvendo sete variáveis e o Produto Industrial, adverte que a pior fase do ciclo deve ter terminado, o que não significa a entrada numa fase de forte crescimento. Pode ser apenas um crescimento menos negativo ou ligeiramente positivo. Suas observações se prendem ao, perfodo 1974-78, em que o modelo se mostrou com boa capacidade preditivel. Toda a questão reside em saber-se se esse conjunto de variáveis, eficaz para os anos de 1979 e 1981, continuará válido para os anos vindouros.

As taxas de desemprego continuam altas, embora tenham diminurdo em Salvador, Porto Alegre e Belo Horizonte, tomando-se março de 82 e 
março de 81 para comparação, e aumentado em São Paulo, Rio de Janeiro e Recife, o que demonstra reações menos uniformes ao longo do território.

A Fundação Getúlio Vargas afirma que "o comportamento da economia brasileira no primeiro quadrimestre do ano foi marcado por claros sintomas de recuperação, o que seria reforçado no in ício de maio por duas medidas básicas: redução do IOF e a retirada do limite de expansão do crédito das financeiras". " A indústria automobilística é citada como exemplo, por ter se expandido nos dois últimos trimestres e por ter produzido mais veículos no período janeiro/março de 1982 em relação a igual período de 1981 . Quanto a este último dado parece haver um equívoco, pois para uma produção de 230.895 veículos em 1981, fabricou-se, agora, 190.452 , ou seja, $18 \%$ a menos. Quanto ao maior volume do primeiro trimestre de 1982 em relação ao último de 1981 , há razões para a firmativa, poịs seus $4,9 \%$ a mais contrastam com os 30\% a menos observados em 1981 em relação a 1980. Há, portanto, uma reação no primeiro trimestre deste ano de 1982, mesmo permanecendo por baixo do volume assinalado em 1981.

Os "claros sintomas" da FGV, contudo, podem não se confirmar, porque uma constante na economia dos últimos três anos, ou seja, tanto na sua tendência expansionista (1979 e 1980) como em seu retraimento (1981) é apresentar os meses de abril a julho marcados por sazonalidade positiva. Independente do resultado líquido anual, esse quadrimestre vem apresentando sempre um movimento ascendente. (Gráfico 2).

Os dados sobre cimento, aço e energia (FIBGE) indicam redução do consumo, o que não deixa de ser significativo por se tratarem de insuimos difundiáos e de uso obrigatório. Tanto em relação ao primeiro trimestre do ano anterior como em: relação ao seu último trimestre o emprego desses bens continua menor, com a única exceção do aço que praticamente se estabilizou.

- consumo de cimento:

$\underline{\text { janeiro - março de } 1982}=0,98$

janeiro - março de 1981

$\underline{\text { janeiro - março de } 1981}=0,90$

outubro - dezembro de 1981

(1) "Conjuntura Econômica", maio, 1982, p.31. 
- consumo de aço:

$\underline{\text { janeiro - março de } 1982}=0,81$

janeiro - março de $1981 \quad$ outubro - dezembro de 1981 $\underline{\text { janeiro-março de } 1982}=1,01$

- consumo de energia:

$\frac{\text { janeiro - março de } 1982}{\text { janeiro - março de } 1981}=0,88 \quad \frac{\text { janeiro - março de } 1982}{\text { outubro - dezembro de } 1981}=0,97$

GRAFICO 2 - INDICADORES DA PRODUÇAOO INDUSTRIAL - BRASIL BASE FIXA

(BASE: MEDIA DE $1975=100$ )

INDICADOR GERAL

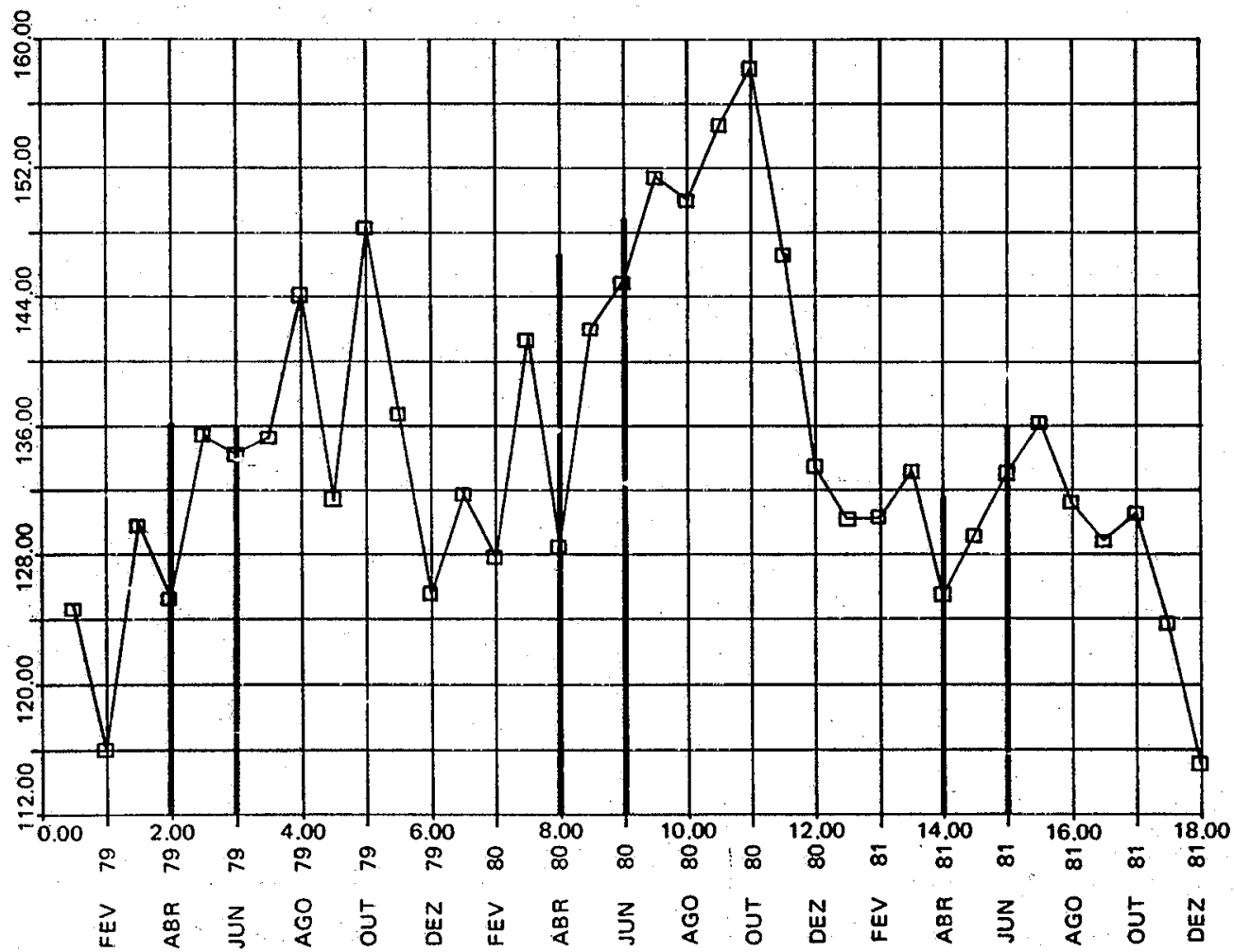

FONTE: FUNDACAOO IBGE

EXECUÇX̃O: IBGE/DT/SUEGE/DEGEO/DIATA - DATA DE APURACÃO: 09/02/82

FIBGE, "Indicadores Conjunturais da Indústria"” - 1981 
Pela Sondagem Conjuntural ( $\mathrm{n}^{\mathrm{O}}$ 63) levada a efeito pelo $\mathrm{FGV}^{1}$, sabese que a previsão dos empresários para o segundo trimestre era de uma procura global crescente $(45 \%)$; de estabilidade (35\%); e de queda $(20 \%)$, enquanto em abril apenas $24 \%$ encontraram uma demanda global forte. Somente $9 \%$ dos empresários entendiam seus estoques excessivos; $55 \%$ encontravamse normais; $3 \%$ os achavam insuficientes e $29 \%$ estavam sem estoques.

No mês de abril, apenas $7 \%$ dos empresários investigados estavam em expansão e os restantes $93 \%$ apresentavam as seguintes limitações:

insuficiência da procura

matérias-primas e/ou componentes

capital de giro

outros fatores

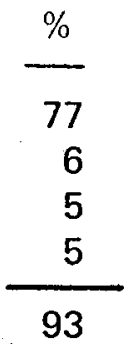

A capacidade ociosa média era de $24 \%$.

A opinião que se possa formar a respeito do tema vai depender de um maior acúmulo de base empírica e da própria interpretação que se fizer do quadro recessivo que aí está. Em última análise, o entendimento que se tiver da própria economia brasileira é que pode trazer luz à questão, mais até do que possa ser apresentado em termos numéricos de um ou outro mês. Um mínimo de esforço de análise, tratando de identificar causações entre os fatos observados e cie distinguir o que se poderia chamar de cenários interno e externo, bem como as relações entre ambos, parece de absoluta imprescindibilidade.

\section{CENARIO INTERNO}

A forma mais prática e direta para encontrar-se uma perspectiva dentro do quadro atual é indagar quais foram as forças responsáveis pelo período de expansão, desaparecidas do cenário. 0 juízo que se possa fazer de cada uma delas permitirá a montagem de um conjunto de possibilidades que, em úitima análise, responderá pelo tempo de reconversão da tendência.

(1) "Conjuntura Econômica", maio, 1982, p.93/95 e 10 i 


\subsection{Mercado Externo}

As exportações brasileiras antes de mais nada constituiram uma clara opção de crescimento, procurando o país abrir espaços nos mercados internacionais como forma primária de geração de impulsos. Nos anos imediatamente anteriores à crise, 1979 e 1980, o "quantum" das exportações se expandiu em $9,7 \%$ e $22,6 \%$, respectivamente, acompanhado também de preços mais elevados em $0,7 \%$ e $5,9 \%$. O Brasil, portanto, ainda desfrutava de uma situação sustentando o nível de emprego das atividades voltadas para o exterior. A partir de 1981, o panorama começa a inverter-se, pois se é verdade que o "quantum" ainda apresenta uma taxa elevada os preços dão mostras de uma queda inequívoca. Encerra-se o exercício com um "quantum" $20 \%$ maior, porém com preços $5,4 \%$ menores. $O$ valor $F O B$ das exportações logrou ainda ser $15,7 \%$ mais elevado do que 1980 , porém isso representa apenas a metade do incremento ocorrido no ano anterior. ${ }^{1}$

O ano de 1982 entra sem sinais de melhor "performance", pois o primeiro trimestre comparado com igual período de 1981 mostra um valor de exportação $4,3 \%$ menor. Os produtos industrializados ainda mantinham o mesmo nível de 81 , porém os produtos básicos (38\% da pauta) já haviam caído que $11 \%$, o que toma realce quando comparado com os $40 \%$ positivos do periodo anterior.

Além dessa contração, caberia também observar a substancial redu. ção do poder de compra das exportações brasileiras em razão da diferença de evolução dòs preços. Enquanto os preços de todas as importações, não só o petróleo, continuam subindo, os preços das exportações começam a declinar ou a subir mencs, como é o caso dos bens de consumo final não-duráveis e os bens de capital. Tomando-se os preços de 1977 para base 100, chega-se ao primeiro trimestre de 1982 com uma relação de intercâmbio de 45, o que significa dizer que o país deve exportar mais do que o dobro para lograr o mesmo volume de importações. No inf́cio de 1982 nenhuma mudança teve lunar nessa tendência, tomando cada vez mais dificil, do ponto de vista do financiamento interno, a manutenção desses fluxos.

Vislumbra-se assim difícil que a economia brasileira possa esperar de seu setor externo algum estímulo de maior peso e até mesmo a simples estabilizaçãc da situação desfavorável de 1981. E verdade que a base empírica para essa convicção é pouco estreita, porém é o próprio quadro internacional a ser referido mais adiante que dá maiores elementos para a mesma.

(i) Em 10 US\$: $1979 \cdot 15.244 ; 1980 \cdot 20.132 ; 1981 \cdot 23.293$. Fonte:CACEX. 


\subsection{Restrição de Crédito}

Toda política creditícia vigente é de extrema cautela expansionista com vista a manter a inflação sob rigoroso controle. O Governo fixou o teto de expansão do crédito em 50\% e mesmo que não logre mantê-lo é difícil que haja qualquer liberalidade. Os resultados de 1981 convenceram o Governo a dar maior abertura no primeiro trimestre, porém quando qualquer afrouxamento repercute imediatamente no nível de preços, não se pode esperar que se corra o risco de pôr a inflação num nível não desejável. O Governo vem reiteradamente afirmando que é necessário manter os meios de pagamento sob rigoroso controle se é desejo continuar com os objetivos de inflação e balança de pagamentos na mira prioritária.

Essa parece ser também a percepção empresarial, quando apenas $2 \%$ dos entrevistados em abril responderam que acreditavam numa expansão do crédito. Mesmo que isso não implique em seus desejos, essa convicção parece realista, pelo menos o suficiente para pautar suas decisões no campo dos negócios. Os que já estão a braços com dificuldades acumuladas desde o ano anterior se sentirão pouco animados para ações expansionistas, particularmente sabendo que há restrições palpáveis ao seu redor como é o caso do crédito.

O informativo Análise em seu número 16, de 27 de abril, registrava uma redução de $1,2 \%$ nos meios de pagamento no mês de março e de $6,3 \%$ no ano, assinalando que a meta oficial de expansão é de $50 \%$ contra $73 \%$ do ano de 1981. Essas cifras não deixam dúvidas quanto ao panorama creditício para o ano corrente.

\subsection{Contenção dos Gastos Públicos}

Essa é uma variável que está sob rigoroso controle do Governo, inclusive com redução dos gastos programados. Já no primeiro mês do ano a despesa do Tesouro Nacional se mostra com uma queda mais acentuada do que a verificada no ano anterior, denunciando a determinação das autoridades nesse sentido. ${ }^{1}$

\subsection{Restrição e Importações}

O menor nível das exportações em termos de valor e a necessidade de contar com um superavit comercial para fązer frente à divida, obriga um efi-

(1) A Fundação de Economia e Estatística em sua "Conjuntura da Economia" 2. trimestre 1982, p.51, registra uma redução de $6,98 \%$ nas despesas efe tivas do Tesouro 
caz policiamento das importações. As taxas dos três primeiros meses do ano em relação a igual periodo do ano anterior não deixam dúvida a respeito: ${ }^{1}$

Janeiro

Fevereiro

Março
Exportação

$-0,7$

$-15,2$

3,1
Importação

$$
\begin{array}{r}
-9,4 \\
-24,0 \\
-9,2
\end{array}
$$

A necessidade de US $\$ 13,6$ bilhões prevista pelas autoridades para fechamento das contas externas parece insuficiente, não só porque se torna difićllimo atingir US\$ 3 bilhões de superavit previstos como porque a própria tomada de recursos no mês de maio mostrava uma tendência decrescente. As reservas em abrii eram menores do que as de dezembro, revelando o ano difícil que se delinea nesses primeiros meses.

Se o país não vai poder expandir suas importações, necessariamente contará com um freio para elevar seu nível do Produto e do Emprego, na medida em que os insumos e bens dt-capital provenientes do exterior estarão com oferta limitada. Isso pode estimular a substituição de importações e, conseqüentemente, ter papel positivo, porém, não o fará nem no curtíssimo prazo nem com a economia em baixa.

$\mathrm{Na}$ pouca elasticidade das importações em 1982 reside um fator a mais de dificuldades a ser enfrentado pela economia nacional, desenhando um quadro de pelo menos muita cautela. Nada autoriza otimismos gratuitos e crenças irresponsáveis sobre "fundo do poço", "fim de recessão", "teto mais baixo", etc, etc..

\subsection{Problemas Estruturais}

Ainda que as causas apontadas anteriormente concorram para o quadro recessivo, é preciso ampliar a ordem de considerações para dispor-se de maiores horizontes, por certo mais completos para a análise da economia brasileira. Celso L. Martone ${ }^{2}$ lembra algumas relações estruturais cuja permanência inviabiliza qualquer tentativa de dar continuidade ao desenvolvimento atual. A partir de 1974 nota-se no Brasil:

a) Poupança interna: o coeficiente de poupança baixou de $26,5 \%$ para $20 \%$, entre $1973-74 / 1979-80$, sendo que o do setor público se reduz de $36 \%$ para $23 \%$ e, o privado, de $16,7 \%$ para $9 \%$. Com isso o consumo pessoal

(1) "Simposium", abril 1982, p.43.

(2) "Mudanças Estruturais e Política Econômica". Conjuntura Econômica, maio, 19?2, 
passa de $77,4 \%$ para $85 \%$. Uma redução dessa ordem significa apoiar-se deliberadamente em recursos externos para crescer. Não se trata, portanto, de ir buscar no exterior complementação aos recursos nacionais, mas de estabelecer uma dependência crescente, a ponto de se dispensar os próprios recursos nacionais de sua contribuição aos investimentos.

E claro que uma política de dispor de uma soma maior do que a produzida internamente leva a três conseqüências imediatas. Primeiro, só funciona a curto prazo, porque não se pode contar com um débito acumulado, crescente e eterno. Segundo, se é para traduzir-se em maiores exportações, ou seja, em superavit comercial, pode não alcançar maiores resultados do ponto de vista do desenvolvimento, quer pelo desfalque da oferta implícito no superavit quer pela relação de trocas imperante entre centro e periferia.

Finalmente, se não for para alimentar um superavit só pode ser para nutrir um déficit, ou seja, uma cümpra dos países centrais que não poderiam vender seus volumes de bens e serviços sem que cedessem crédito para sua aquisição. Em última análise, a redução do coeficiente de poupança interna pode estar ligada à necessidade de estimular o mercado dos países desenvolvidos, funcionando por isso mesmo como desestímulo aos produtores internos.

Parece evidente que a redução do coeficiente de poupança interno além de não consultar os interesses do desenvolvimento nacional implica em política de curto prazo. Sempre quando se a quer transformar em política de desenvolvimento expõe suas limitações e passa a configurar um escolho a mais a ser superado.

O Brasil tem que elevar seu coeficiente de poupança como uma das condições de encontrar maior fluidez em seu financiamento, ao mesmo tempo que abrirá espaço para a alocação de recursos segundo os interesses na cionais.

b) Maior investimento com repercussão no Balanço de Pagamentos: a tentativa de elevar o nível do investimento sem um adequado programa de substituição de importações acarretou um aumento desmedido do déficit em conta corrente, que de $2,2 \%$ do PIB, em 1973-74, passa para 4,9\%, em 1979 . 80. O curioso é que foi sob a alegação de um ambicioso programa de substituição de importações de insumos básicos e de bens de capital, bem como de desenfreada expansão da infraestrutura, que se criaram os déficits, ou seja, os estrangulamentos que hoje emperram o país. Se a isso for adicionado o aumento do consumo via gasto público, programás sociais e crédito subsidiado, tem-se um somatório a mais de pressões no setor externo, além da disputa que todos esses objetivos simultâneos geraram pelos recursos internos. 
A tentativa desordenada e assistemática de tudo fazer sem qualquer estratégia de médio e-fongo prazo, sem coerência e compatibilidade entre fins e meios, redundou como não podia deixar de ser num impasse, onde toda a economia ficou na dependência de uma estrutura de gasto absolutamente inconsistente em termos de composição, volume, financiamento, componente importado e viabilidade social.

$E$ indispensável encontrar uma nova estrutura de gasto, onde todos os aspectos citados sejam colocados em outros termos, de modo a que se recobra o dinamismo perdido e se encontre seqüências que passem pela capacidade ociosa instalada, pelos mecanismos internos de financiamento e pelos mais amplos interesses da população.

c) Baixa na relação Produto/Capital: entre os dois anos referidos, o coeficiente baixa de 0,56 para 0,35 , o que significa uma redução de mais de $40 \%$ do Produto por unidade de capital instalado. Essa considerável perda de produtividade traduz custos crescentes no sistema e inevitáveis pressões inflacionárias deles decorrentes. Essa redução é medida antes de 1981, portanto sem os efeitos recessivos deflagrados nesse ano e deve estar refletindo investimentos com grande período de amadurecimento. Esse é um dado diff́cil de contornar não só pelos interesses que gravitam em torno dele como polas deseconomias que pode acarretar qualquer mudança. De qualquer maneira trata-se de um parâmetro que não pode ser ignorado no quadro atual, uma vez que perda de produtividade no conjunto da economia significa baixa de eficiência no uso dos recursos, cujo contorno por mais que se imponha muitas vezes se apresenta incerto.

d) Queda no grau de abertura: as exportações que representavam $7,4 \%$ do PIB passam para $6 \%$, em que pese os consideráveis recursos canalizados via benefícios fiscais e subsídios. Ao contrário dos países desenvolvidos que aumentaram sua participação nas exportações mundiais mais do que a do seu Produto, o Brasil recuou nessa relação, mostrando sua incapacidade relativa de aumentar sua posição no mercado internacional. Todo o esforço de canalização de recursos e as prioridades estabelecidas foram para abrir a economia brasileira, internalizá-la, mesmo em detrimento dos interesses internos. O descomunal encaminhamento de recursos para o setor externo, cuja aferição mais simples se traduz nos subsídios que atingiram a quase um terço da arrecadação fiscal da União, terminou por não engendrar maior fixação no coeficiente já atingido, porque a situação do mercado externo täo pouco autorizava maiores ilusões.

O modelo exportador terminou por não produizr os efeitos desejados, mas em compensação comprometeu profundamente os recursos nacio- 
nais com suas exigências de vender a qualquer preço. $O$ Brasil diminuiu sua poupança interna, o que implicava na opção de dependência de recursos externos; se voltou para fora, a fim de gerar as divisas que essa opção exigia; passou a vender muito abaixo de seus custos, porque não tinha competitividade capaz de fazer frente aos preços internacionais; se compromete a vender cada vez mais artificialmente baixo para aumentar volumes claramente recusados num mundo em recessão. $O$ custo dessa política tem reflexos imediatos na contração do mercado interno, tendo em vista o encarecimento generalizado dos bens e serviços para ele voltados, decorrente do ônus dos subsídios e outros artifícios, ou da renda subtraída aos fatores a ser filtrada para fora via preços artificiais.

A busca de dinamismo pelo setor externo redundou numa perda de dinamismo das atividades internas, o que compromete os resultados líquidos, considerando que elas totalizam $94 \%$ do PIB. Isso põe em dúvida se foi para resolver problemas brasileiros que essa política foi adotada, embora nenhuma subsista quanto a impossibilidade de sua continuidade.

e) Aumento no grau de dependência das importações: o festejado programa de substituições de importações terminou elevando o coeficiente de importações sobre o PIB de 9,5 para 10,3, pondo a descoberto a inconseqüência da política executada. A falta de uma programação séria e a desordenada ocorrida pelos recursos terminaram tendo seus reflexos nas importações. Uma queda no coeficiente das exportações e uma subida no das importações só se viabiliza com complementações de recursos externos, ou seja, com maior dependência de recursos financeiros e de recursos reais, cuja participação crescente revela menores graus de liberdade para decisỗes independentes.

Maıor dependência de um, maior independência para outro. Na medida em que o Brasil abriu mais o seli mercado do que o logrado com suas exportações submeteu-se a uma filtração do estímulo externo, prejudicial ao seu próprio desenvolvimento. O menor mercado para o Brasil significou o maior mercado para os outros, no momento em que o mercado como um todo se retrai. $O$ endividamente e o aumento das importações são reflexos de um mesmo fenômeno, onde a abundância de recursos financeiros e a capacidade ociosa dos países centrais encontram escape nos países periféricos.

A simples diferença entre importação e exportação não significa dano para um país, uma vez que nã̀o constitui uma maldade em si contar com uma soma de bens e serviços maior do que o produzido internamente. $O$ problema todo reside na função desse desequilíbrio, em seu papel no processo de acumulação e desenvo!vimento, e na sua assimilação a médio e longo prazos. A maior prova de que à elevação do coeficiente de importação se efetivou à 
margem de qualquer consideração dessa ordem está na política atual de seus cortes mais indiscriminados, sem que se tenha completado qualquer programa capaz de dar suporte às etapas subseqüentes.

f) Concentração de renda: se a distribuição extremamente concentrada da renda nacional deixou de plasmar uma estrutura de demanda dinâmica, a ponto de tentar-se via inflação, ou seja, maior concentração, efeitos adicionais, dever-se-ia esperar urna política de sentido contrário justamente para alimentar um novo tipo de crescimento. Isso não foi feito e o Censo de 1980 não revela qualquer avanço nesse terreno. A idéia de que por lei se vai redistribuir renda, como é o caso dos $10 \%$ a mais nos reajustes dos níveis inferiores, não deixa de ser inocente, porque com o al to coeficiente de desemprego é impossível manter salário real elevado. Com o expediente da rotação da mão-de-obra é fácil achatar o salário, mesmo porque não há lógica nenhuma em pensar que o menor custc não expele o maior.

Como essa concentração de renda teve função na dinâmica anterior e como é difícil admitir seu agravamento por "mecanismos consentidos", o que levou ao emprego da inflação como meio de despojo de um grupo social por outro, não é menos difícil entender que ao nível em que chegou a inflação possa ela continuar tendo alguma funcionalidade fecunda. A subtração de renda por mecanismos "visíveis" - legais, tributários, etc. - foi acrescida por mecanismos "invisíveis" como a inflação, só que agora já é difícil manter essa clandestinidade, o que torna o intento inteiramente impotente.

Como nãc se faz redistribuição de renda da noite para o dia e tão pouco apenas pelos mecanismos de mercado, a montagem de um aparato institucional que the dê efetivo suporte se torna imprescindivel. Nada foi feito nessa direção, porque se continua acreditando na eficácia de institutos legais para enfrentar questões de natureza econômica e social. A concentração da renda no Brasil tornou-se um obstáculo à dinâmica da acumulação, po rém dela ainda não partiu nada que al tere o impasse atual.

g) Financiamento público: a Carga tributária passa de $24,8 \%$ do PIB para $21,9 \%$ entre $1973-74 / 1979-80$, e a Carga líquida de $16,5 \%$ para $12,8 \%$, deslocando-se assim o financiamento para a dívida pública e para a inflação. A Dívida Pública Interna passa de $7,5 \%$ para $12,5 \%$; a Dívida Pública Externa, de $8,1 \%$ para $15,7 \%$.

A primeira observação a fazer é quanto a carga tributária que muitos entendem excessiva. Como marco comparativo é bori saber que. em 1938, 
a carga fiscal americana já era de $25,6 \%$ e que a inglesa chegava aos $24,1 \%^{1}$, ficando a carga bruta francesa em $22,8 \%$ e, a líquida, em $22,1 \%{ }^{2}$ Saber também que pelo início do século elas se aproximavam dos $10 \%$, deixando claro qual a sua tendência nas sociedades modernas. As cargas tributárias dos países desenvolvidos são superiores a 30\%, não constituindo a carga brasileira nenhuma aberração como querem muitos. Mesmo considerando as diferenças de produtividade, o que significa também diferenças temporais entre os países, o coeficiente brasileiro se situa dentro dos padrões internacionalmente conhecidos.

A segunda observação sobre o assunto prende-se a que o ônus fiscal já foi maior no Brasil, o que reforça ainda mais a improcedência sobre seu excesso:

$\begin{array}{lcccc} & 1950 & 1960 & 1973-74 & 1979-80 \\ \text { Carga fiscal bruta } & 20,2 & 26,9 & 24,8 & 21,9 \\ \text { Carga fiscal líquida } & 16,0 & 21,0 & 16,5 & 12,8\end{array}$

Além dessa regressividade dá carga tem-se a sua extrema atenuação quando se consideram as devoluções do tributo pelos subsídios e outras formas de transferências. Quando se olha a carga fiscal liquida de 1979-80 fica-se com a mais absoluta convicção de tratar-se das mais baixas do mundo. Tanto evoluiu a política fiscal brasileira nesse sentido que, em 1956, o Tesouro Nacional devolvia $21 \%$ do que arrecadava e, em $1979-80$ chegou aos $42 \%$, ou seja, o dobro.

Essa liberalidade generosa com seus recursos, ao mesmo tempo em que seus gastos não diminuiram, levaria inevitavelmente a outra forma de financiamento: dívida pública e inflaçăo. A dívida pública interna passa de $7,5 \%$ do PIB para $12,5 \%$, entre $1973-74$ e 1979-80, enquanto a divida pública externa também aumenta de $8,1 \%$ para $15,7 \%$ no mesmo período. A inflação dispensa comentários.

O Tesouro abriu mão de seus recursos para ir solicitá-los no mercado de capitais, disputando com os empresários, à taxa de juros deliberadamente alta, o financiamento de que carecia. Esse caminho de obtenção de recursos, ao pressionar os juros para cima, provocou elevação de custos e pressões inflacionárias. Os tetos, entretanto, alcançados pelos juros e pela inflação não

(1) Felipe Herrera Lane, "Fundamentos de la Política Fiscäl", Editorial Jurfdica de Chile, 1951, p.63.

(2) Henry Laufenburger. "Traité D'Economie et de Législation Financières - Revenu, Capital et Impot", Recueil Sirey, Paris, 1950, p.335. 
mais o credenciam como rota segura e por isso mesmo o transformam em mais uma variável que se enrigece.

A falta de liquidez em dólares estimula a divida pública externa, isto é, estimula o Governo a financiar-se via endividamento nacional. Mesmo que ainda encontre alguma elasticidade para mover-se é difícil que as margens sejam muito amplas, o que torna a alternativa limitada.

O financiamento público é sem dúvida outra questão pendente de solução e, assim, outra força contrária à retomada do dinamismo perdido. Pode ser resolvido a curto prazo?

\subsection{A Título de Síntese}

Quando se pergunta objetivamente o que esteve presente na etapa anterior e que acaba de deixar o cenário, pervertendo a tendência até então despertada, tudo aponta para as margens com que se alocavam os recursos e para as formas de financiamento empregadas até há pouco. O crescimento para fora, a mobilização dě recursos externos, o artificialismo dos custos, o volume de gasto, o suporte de uma renda em concentração e os mecanismos de financiamento formam um conjun to de peças que submetido a desgastes diferenciados perde a solidez de seus componentes e já não mais consegue as mesmas articulações de antes.

A inflação, por exemplo, é uma das tantas variáveis utilizadas como força de propulsão. Em $1972-73$ estava no patamar dos 15\%, disparando rápido para os 46\% três anos depois. Quando em 1977 se procurou pôr freio nessa corrida, logrando-se confiná-la nos limites de $38,8 \%$, imediatamente o Produto se despenca dos 10,4 para $3,9 \%$, dando a impressão de que o país havia parado. A tolerância em seguida com níveis inflacionários mais abertos foi também a necessidade de um crescimento mais rápido, configurando claramente que a inflação era um componente de demanda que não podia ser desprezado. O problema todo é que só uma inflação crescente é estimuladora, pois se permanecer no mesmo nivel já gera contração na atividade.

Se o país conta com uma considerável capacidade ociosa e não consegue aproveitá-la para crescer, um redirecionamento do gasto público - variável autônoma do sistema - poderia ser o remédio mais prático e imediato disponível. Se os projetos prioritários do Governo reunissem essa capacidade o Produto não estaria comprimido. A maior demonstração de extemporaneidade da atual prioridade de gasto reside no incrível paradoxo de se estar criando capacidade produtiva quando o país conta com excesso de capacidade instalada e sem que haja a mínima compensação entre uma e outra. Não é por falta de capacidade que o país não cresce, mas por abundância. Sem se 
mudar o perfil do gasto, ou seja, a estrutura da demanda, como aproveitar o capital ocioso e a mão-de-obra desempregada da nação? O Governo, contudo, não fala em mudar, mas em reduzir, para aliviar a pressão inflacionária.

A opção de um modelo exportador deveria estar acompanhado por um grande cuidado com as filtrações, não permitindo que os estímulos entrados pelas exportações tivessem fácil saída pelas importações desproporcionais. Issso só não funcionou como força depressiva porque foi compensado por uma inflação permanente, ou seja, por uma transferência de renda de um grupo social para outro. A demanda que se mantinha via transferência e que alimentava uma parte da demanda, faltaria necessariamente, pela mesma transferência, para a outra parte. Quanto mais se insistiu no desequilíbrio externo mais se reclamava por transferências internas, tentando desesperadamente manter pelo menos ocupado as atividades de ponte. Não é por acaso que a concentração da renda aumentou ou se manteve em que pese o crescimento desta e os ganhos de produtividade na década. A inflação precisava apenas de um pretexto, pois a razão objetiva já estava mais do que dada. 0 "petróleo" caiu do céu ${ }^{1}$ e os subsídios desenfreados, particularmente os destinados à exportação, se revestiram de verdadeira causa patriótica. 0 pretexto, contudo, não tem nenhuma importância, mas, sim, o que de objetivo provoca e, no caso, provocou a sustentação de um crescimento cuja taxa média industrial ficou em 7,5 (1974-80), perfodo em que paises altamente industrializados registravam taxas insignificantes: Alemanha, 1,2; Japão, 2,8; EE.UU., 1,8; Reino Unido, $-0,6 .^{2}$

Provavelmente a crise de 1981 estaria arrebentando em 1974, ocasião em que a inflação dobra sua taxa, anunciando uma grande necessidade de injeção de demanda. Se a polftica econômica em várias direções não tivesse contado sempre com a inflação, que é o mesmo que dizer que só se mostrou conseqüente porque não partiu da exigência de um nível de preços constante, revelaria cedo a profundidade da crise e a necessidade de identificar outras alternativas para seu enfrentamento.

Se a crise latente já se desenhava em 1974, não se pode tirar o mérito de seu controle até 1980. Foram seis anos em que as forças produtivas cresceram, embora o grande custo social implícito. Porém, esse custo social foi maior do que o derivado do desemprego que ocorreria?

(1) Parses que têm muito maior consumo "per capita" de petróleo do que o Brasil e não menor dependência de suas importaçōes registram taxas de inflaçáo incomparavalmente menores, no periodo 1973-80: Alemanha, 4 8; Japð̌o, 9,7; França, 11,1; Bélgica, 8,1. A do Prasil andou por $54,8$.

(2) FGV, "Conjuntura Económica", março, 1982, p.69. 
Pode-se discutir até à saciedade os caminhos alternativos de antes e de agora, porém não se pode deixar de ver na abertura para o exterior, nas filtrações, na estrutura do gasto, na concentração da renda, nas origens e formas do financiamento e, afinal, no estancamento, um todo harmônico e funcional. Querer isolar um ou outro desses aspectos é assumir o risco de abstrações perigosas e ser conduzido a soluções simplistas, porque induzidas por visões parciais. E esse "sistema" que também impõe um tempo mínimo de reconversão, uma vez que não se está na presença de um mero desequilíhrio localizado, cuja correção devolve fluidez ao todo. A crise de 1963 só encontra sua solução em 1968, quando a economia volta a usufruir de taxas "per capita" elevadas. Naquela ocasião a indústria não chegou a registrar taxas negativas, ao contrário desta quando seu decrescimento é mais forte do que o do Produto. Para um país muito mais urbanizado que antes uma quebra tão forte no setor manufatureiro tende a um efeito multiplicador extenso. O marco de duas décadas atrás pode servir de advertência aos que imaginam soluções fáceis e milagrosas.

Finalmente surge a questão da economia internacional onde o Brasil se insere irrecusavelmente. Agora, há uma crise generalizada; em 1964, a economia estava em plena velocidade.

\section{CENARIO EXTERNO}

\subsection{Crise Internacional e sua Interpretação}

No final da década de 20 o Times de Londres publicava uma tabela abarcando um período de 138 anos, entre 1781 e 1919, em que identificava 16 crises e 16 fases de prosperidade, o que úava uma média de quase rove anos para cada ciclo. ${ }^{1}$ Por seu turino, Mandel registra que desde a formação do mercado mundial do capitalismo industrial houve exatamente vinte crises de sobreprodução, enumerando: 1825, 1836, 1847, 1857, 1866, 1873, 1882 , 1891, 1900, 1907, 1913, 1921, 1929, 1937, 1949, 1953, 1958, 1961, 1970 e a 1974-75, cuja média anda em torno dos 8 anos. $^{2}$

A observação dos fatos econômicos levava também a registros de outro tipo. Entre 1922 e 1928, o Prof. Nicolai Dmitrievich Kondratieff, da Academia da Agricultura e do Instituto de Investigações Econômicas de Moscou,

(1) Richard B.Day, "La Teoria del Ciclo Prolongado de Kondratieff, Trostsky y Mandel", em "El Estado y la Crisis". Ediciones El Cáhallito, México, 1977. p.57, ITrata-se de uma citação de Trostky, feita por Day).

(2) Ernest Mandel, "La Crisis 1974-1980", Serie Popular Era, México, 1980, p.44. 
desenvolvia estudos e constatações que lhe levaram a declarar: "Quando em Economia se fala em ciclos, de maneira geral se trata de ciclos de sete a onze anos. Mas esses não são evidentemente o único tipo de ciclos econômicos. Em realidade, a dinâmica da vida econômica é mais complicada". Além desses ciclos que ele denominou de "ciclos médios", poder-se-ia encontrar ondas de uma duração média de 3,5 anos (Kitschim) e outra de 50 anos, que acabariam tomando seu nome. "Por conseguinte, diz ele, se às ondas médias se somam outras, largas e curtas, não cabem dúvidas de que o problema da dinâmica econômica se apresenta muito complicado"..

Consoante com essa visão de longo curso, Samir Amin assinala quatro fases de expansão - 1815-40, 1850-70, 1890-1914, 1948-67 - e quatro fases de crise: $1840-50,1870-90,1914-48$, e o período pós 1967, destacando que cada "fase de expansão caracteriza-se por um modelo particular de acumula: ção, um tipo de indústria motriz, um quadro específico que define as modalidades de concorrência e o estatuto da empresa. Cada uma corresponde a uma certa etapa da expansão geográfica do sistema capitalista, a uma organização particular da especialização internacional nesse quadro e, mais precisa. mente, a uma distribuição das funções de seu centro e de sua periferia, e, finalmente, a um certo equilibrio (ou desequilibrio) entre os diferentes estados-nações centrais"'?

A história do desenvolvimento nos últimos duzentos anos está marcado por esse crescimento ondulatório, de períodos variados das diversas ondas e até mesmo contrários os sentidos com que se apresentam. Num determinado momento pode-se encontrar uma onda de longa duração em sua fase ascendente, coexistindo com outra, de duração média (Juglar), numa etapa descendente e, finalmente, uma terceira, de curto intervalo (Kitchiin), com sentido asceirdente ${ }^{3}$, refletindo uma economia submetida a tensões dos mais diversos tipos. De qualquer modo, são os ciclos de Kondratieff que oferecem as maiores perspectivas para os períodos de prosperidade e que pontualizam também períodos duradouros de desaceleração e retraimento em sứas etapas depressivas. É com referência a eles que se pode formar uma idéia das facilidades, ou não, de conversibilidade de uma determinada situação.

O quadro atual da economia mundial configura uma crise como há muito não se tem notícia. $O$ crescimento industrial se desacelerou brutal-

(1) N.D. Kondratieff, "As ondas Largas da Conjuntura", Revista do Occidente, Madrid, 1946, p. 3 e 4.

(2) Samir Amin, "A Crise do Imperialismo", Graal, Rio de Janeiro, 1977, p.6.

(3) Uma excelente descrição e registro desses ciclos se encontram em Henri Guitton, "Les Fluctuations Economiques", Recuill Sirey, Paris, 1951, p.94-110. 
mente entre as décadas dos 60 e dos 70, o desemprego atinge a níveis comparáveis a 1929 e a inflação não só não cede como dá mostras de querer disparar. O comércio exterior se apresenta pouco dinâmico, a taxa de lucro se reduz, os investimentos caem, o mundo empresarial estala com notícias de insolvências e de fusões de grandes firmas. Os ganhos especulativos no mercado do dinheiro e dos papéis tentam compensar o estiolamento da esfera produtiva, os gastos militares assumem proporções fantásticas, proporcionando lucros que só a presença do Estado pode garantir e que só custos diluidos socialmente podem ser suportados.

Cada ciclo tem sua história particular e sua característica própria, o que não dispensa a sua análise mais atenta para uma clara identificação de sua natureza. Ernest Mandel $^{1}$ entende que a crise atual é resultante de cinco crises de diferentes tipos. São deles as observações abaixo:

a) Crise clássica de sobreprodução - com tentativas heróicas de evitar sua profundiciade e duração através do déficit fiscal e da expansão do crédito em grande escala. $\mathrm{O}$ grande endividamento público e privado, empréstimos aos governos imperialistas mais débeis, aos monopólios mais afetados, aos países do Terceiro Mundo e os países chamados socialistas, tomando o lugar dos créditos aos consumidores e às firmas mais firmes que se entrin. cheiravam em seus recursos próprios. As reações de 1972-73 e 1976-78 foram tentativas de conversão dentro de uma tendência claramente estagnacionista.

b) Inversão da onda larga - que desde os finais dos anos 60 deixou de atuar no sentidn expansionista. As rendas tecnc!b́gicas elevadas, os lucros extraordinários monopolistas realizados curan te muito tempo por ramos avançados como o do automóvel, eletrônica, química, fabricação de utenślios científicos, etc., etc., se reduzem progressivamente ou desaparecem por completo. Uma citação de Orio Giarini parece sintetizar bem a situação para a indústria de fibras sintéticas: "O ciclo chega a certo amadurecimento que já pode ser discernido nos anos 60: os novos inventos que se sucedem não cobrem mais que possibilidades de utilização cada vez mais marginais, decepcionando as esperanças de uma grande ativação. Com o tempo, a investigação se concentra mais no melhoramento do existente. Entramos numa fase evidente de rendimentos decrescentes da tecnologia. Encontramos (...) signos similares em outros âmbitos: no setor das grandes computadoras (...) para IBM, o que estava previsto para 1976 em um programa FS (future system)

(1) E. Mandel, obra citada, p.244.57. 
se posterga para dentro de sete ou oito anos (...) O mesmo (...) na aviação civil." 1

O desaparecimento das rendas tecnológicas constituem um fator a mais a confirmar que a taxa de lucro a longo prazo permanecerá abaixo da verificada nos anos 50 e 60, mesmo considerando as fases de reativação que continuarão a reproduzir-se periodicamente.

c) Crise no sistema imperialista - onde a crise do petróleo não é mais do que um reflexo indireto. Com o rompimento do sistema colonial, onde a dominação centro-periferia passa da forma direta à indireta introduziu-se mesmo de modo marginal uma nova repartição dos lucros entre burguesias imperialistas e classes dominantes dos países semicoloniais e dependentes. Mesmo que isso tenha afetado o lucro mundial num $7-8 \%$, não deixa de ser um dado novo no quadro global.

Além disso, a própria distribuição dos lucros entre os países centrais, modificando suas posições relativas, como é o caso da Alemanha e Japão, e suas influências também na periferia, envolvem alterações profundas no sistema de forças, porque calcadas em vantagens de natureza tecnológica.

d) Crise social e política - decorrente da crise econômica de um lado e da não aceitação por parte das maiorias assalariadas de suportar o seu ônus ou pelo menos seu ônus maior, de outro. Tanto o número de assalariados em greve como o número de dias de greve aumentam significativamente entre os anos 50 e os 70, ou mesmo entre 1971 e anos mais recentes, motrando dificuldades crescentes para descarregar sobre a população salários mais reduzidos e benefícios sociais inferiores. Cada vez mais as soluções fáceis do passado se tornam difíceis no presente.

e) Crise estrutural das relações capitalistas decorrente da conjunção das quatro crises anteriores e das dificuldades que o sistema encontra para continuar elevando o bem-estar, assegurar o pleno-emprego e ao mesmo tempo manter as instituições democráticas e a estrutura jurídica da sociedade. A recessão abala a credibilidade no sistema e põe dúvidas em suas virtudes tão zelosamente cultivadas e prọaladas por sua instância ideológica.

Por fim, assinala Mandel, "ondas longas com tendência ao estancamento não implicam em absoluto uma depressão permanente da produção material que se estenderia de vinte a vinte e cinco anos. Estas se caracterizam por uma sucessão de crises de sobreprodução e de perfodos de reativação e aumento da produção, exatamente como as ondas largas de tendência expansiva. A diferença é que durante as ondas largas de tendência expansiva

(1) Revista "Futuribles", outonn cia 1977. 
as fases de recessão são mais curtas e menos profundas; as fases de expansão e de "boom" mais largas e mais prósperas." Por essa mesma razão, são maiores as restrições para transformar as fases recessivas em prosperidade quando no fundo elas estão subordinadas à "onda larga com tendência ao estancamento".

Poder-se-ia ir longe para uma ampla demonstração da profundidade da crise atual, porém esse não é o propósito dessa exposição. O ritmo do PNB, o estado da capacidade instalada, os graus de endividamento pessoal e público, o balanço de pagamentos e a inflação, quando vistos em suas interrelações e em sua globabilidade deixam sinais de dúvidas e de preocupação. O problema maior é que o Brasil está dentro desse quadro e por isso sofre suas inevitáveis conseqüências.

\subsection{Centro e Periferia}

Cōmo é que os países desenvolvidos vêem suas periferias nos momentos de crise? Um dos traços marcantes da crise é a capacidade ociosa de um lado e a sobre-acumulação do capital-dinheiro de outro. Mandel registrava por exemplo que em 1975 as inversões em eurodólares e eurodivisas alcançou a 200 bilhões de dólares; a meados de 1978, 400 bilhões de dólares. A sua contrapartida real só podia ser uma ociosidade crescente e um grande desemprego. Pois bem, este é o problema central a resolver.

A primeira corrida é no sentido de transformar prejuízos privados em custos sociais, fazendo com que o estado assuma o comando da reconversão. A primeira conseqüência, o descomunal aumento da dívida pública, garantindo-se assim remuneração para um capital que não tem aplicação. A segunda conseqüência, o grande endividamento privado, esfera que passa, por esse expediente, a suprir-se dos recursos que o desemprego lhe está tirando. A terceira corrịda é quanto aos mercados externos, onde a formação de superavit em sua Balança de Pagamentos é condição indispensável como força indutora das economias nacionais e regionais e como elemento importante na manutenção relativa da posição de cada uma. Conseqüências imediatas dessa necessidade são: financiamento, agressividade nas vendas, proteção e resguardo de seus mercados. E justamente aĺ que entra a periferia.

A necessidade de dar aplicação ao capital-dinheiro "cria" a necessidade de tomá-lo, o que leva os países periféricos como o Brasil a um endividamento incomum. Palses como o México, produtor de petróleo, atestán pela inconseqüente alegação de que foi 3 elevação dos preços do combustível a 
causa da iliquidez externa. É inegável que ela estevé presente, porém quando se olha o quadro maior de capitais sobrantes, hierarquizam-se imediatamente as causas em jogo e passa-se a entender o porque do endividamento. Entendese também a "generosidade" dos banqueiros ocidentais em emprestar seus capitais aos "inimigos do oeste".

Atrás do endividamento vem o "deficit" na Balança Comercial, porque a saída ao capital financeiro tem que estar acompanhada com a saída de fluxos de mercadorias, a fim de dar ocupação à capacidade ociosa. A partir dessa percepção as coisas começam a ter lógica e o papel dos agentes assume outra conotação. Será dificil entender porque o Brasil de uma hora para outra começa a importar muito mais do que exporta, a depender furiosamente de recursos externos e abrir sua proteção a respeito de sua própria capacidade instalada e de sua potencialidade de desdobramento? Será difícil entender pcrque a Europa tem uma "obra do século" - o gasoduto siberiano - avaliada em 11 bilłões de dólares, e o Brasil em seus Programas de Governo para o período de 1982-85 tem investimentos orçados em 90 bilh:̃̃es de dólares, ou seja, 8 "obras do século", entre elas nenhuma de natureza social?"

Num parque montado com recursos e interesses externos, sob o comanido dominante de empresas estrangeiras, com os quais os próprios nacionais se associam, não é absurdo pensar que pode esquecer de seus próprios interesses em benefício de uma situação vista e conduzida pelos interesses do Centro hegemônico?

E muito mais fácil manter ociosidade na periferia do que no centro e é por isso que toda a política é montada para corresponder a esse desiderato. Por outro lado, quando o centro se fecha, se protege da competição forânea, que efeitos se pode imaginar de unı politica assentada sobre exportações? Só pode redundar na prática numa colossal transferência de recursos via relação de preços, o que tem muito que ver com a manutenção da taxa de lucro no centro.

Isto não quer dizer que os países periféricos tenham igual sorte e que suas diferenças tanto nas'funções atribuídas pelo centro como as decorrentes dos diversos graus de desenvolvimento de suas forças produtivas não thes assegurem condições peculiares de acumulação. Parece indiscutível que esse mosaico de situações ocultas a subordinação aos mesmos interesses internacionais, e por isso não pode ser entendido fazendo-se abstração desses vínculos.

(1) "Isto e"', julino de 1982, p.80-84. 


\section{CONCLUSÃO}

O Brasil está em crise e o mundo está em crise. A primeira não é independente da segunda, mas guarda margens de autonomia que podem ser mais, ou menos, exploradas. Isso significa que os tempos para uma reconversão não são os mesmos, inclusive porque os ganhos tecnológicos no Brasil têm fronteiras mais amplas do que nos países centrais. Só que o país hoje está carregando à sua crise e a crise dos outros, porque assumiu uma solidariedade com os problemas estranhos à sociedade brasileira - não estranhos aos interesses do processo de acumulação como um todo - que não faz justiça às condições de vida da população e ao atraso em relaçãc aos países desenvolvidos.

Quando se diz que o país carrega a sua própria crise signfica que domina sua própria solução? Ou, que essa solução depende apenas da política econômica de outro tipo? Ou, ainda, que mudando-se pessoas e agentes tudo se reencaminha para outros rumos? Se as crises no capitalismo fossem uma questão de política seguramente não existiriam mais, porque as nações maị avançadas por certo já as teriam neutralizado. Não obstante essa não é uma referência que exima os homens de responsabilidade, porque existem graus de liberdade dentro das tendências que são de competência exclusiva dos interesses em pugna. Essa, entretanto, não é uma questão econômica, mas política. 
TABELA 1

PRODUTO REAL DA INDÚSTRIA BRASILEIRA TAXA ANUAIS

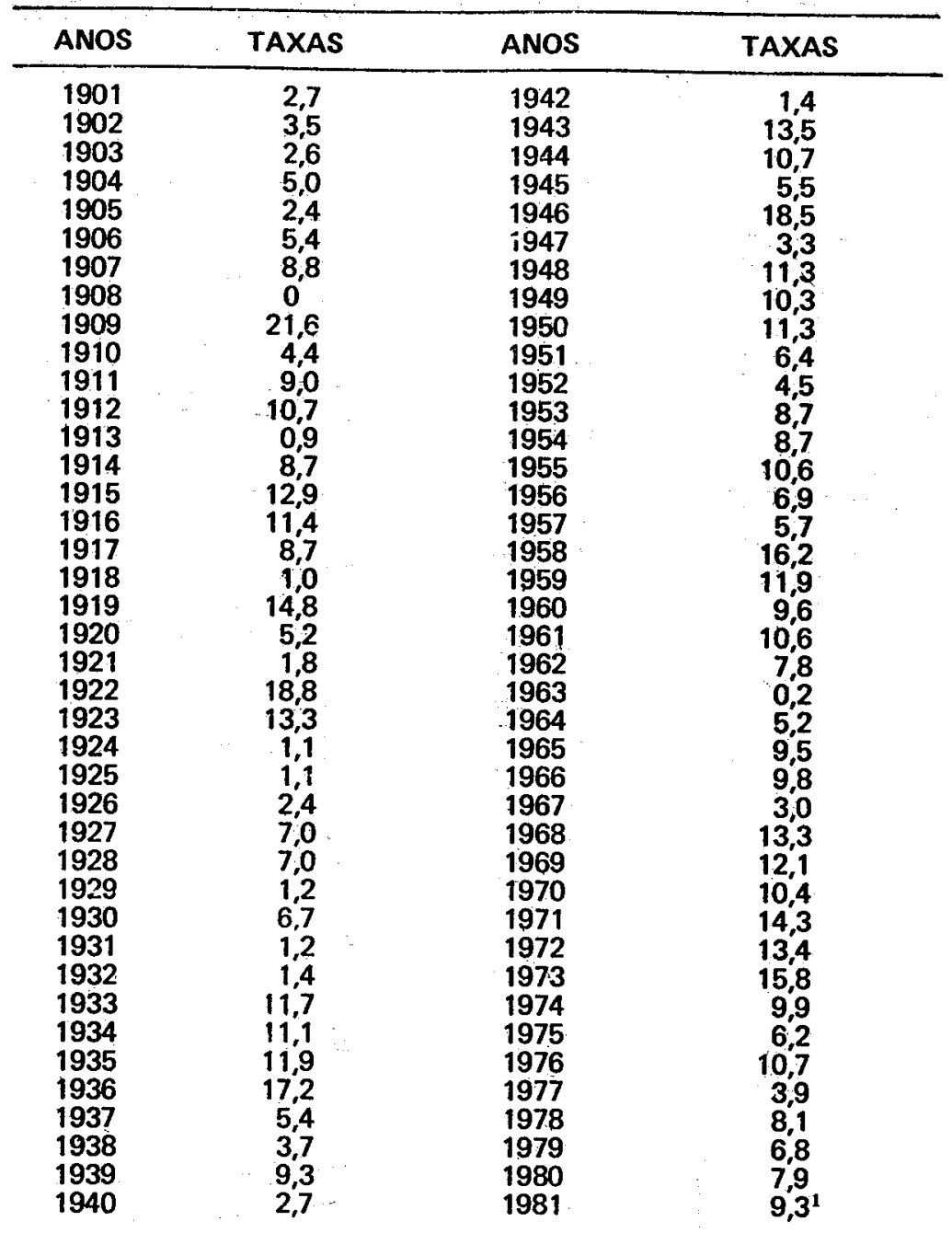

FONTE: De 1900 a 1947, Claudio Haddad, "Crescimento do Produto Real Brasileiro, 1900-1947", ANPEC, Formação Econômica do Brasil. A Experiência da Industrialização", Saraiva, 1977. São Paulo.

Até 1966, F.G.V., "Conjuntura Econômica, no 10, 1969. De 1967 a 1977, "Conjuntura Econômica", no' 12, 1980. Ano de 1980 e 1981, "Conjuntura Econômica", ño 2, 1982.

(1) Essa taxa pode ter sido retificada para - 5,4, "Conjuntura Econômica" no 5, 1982. 


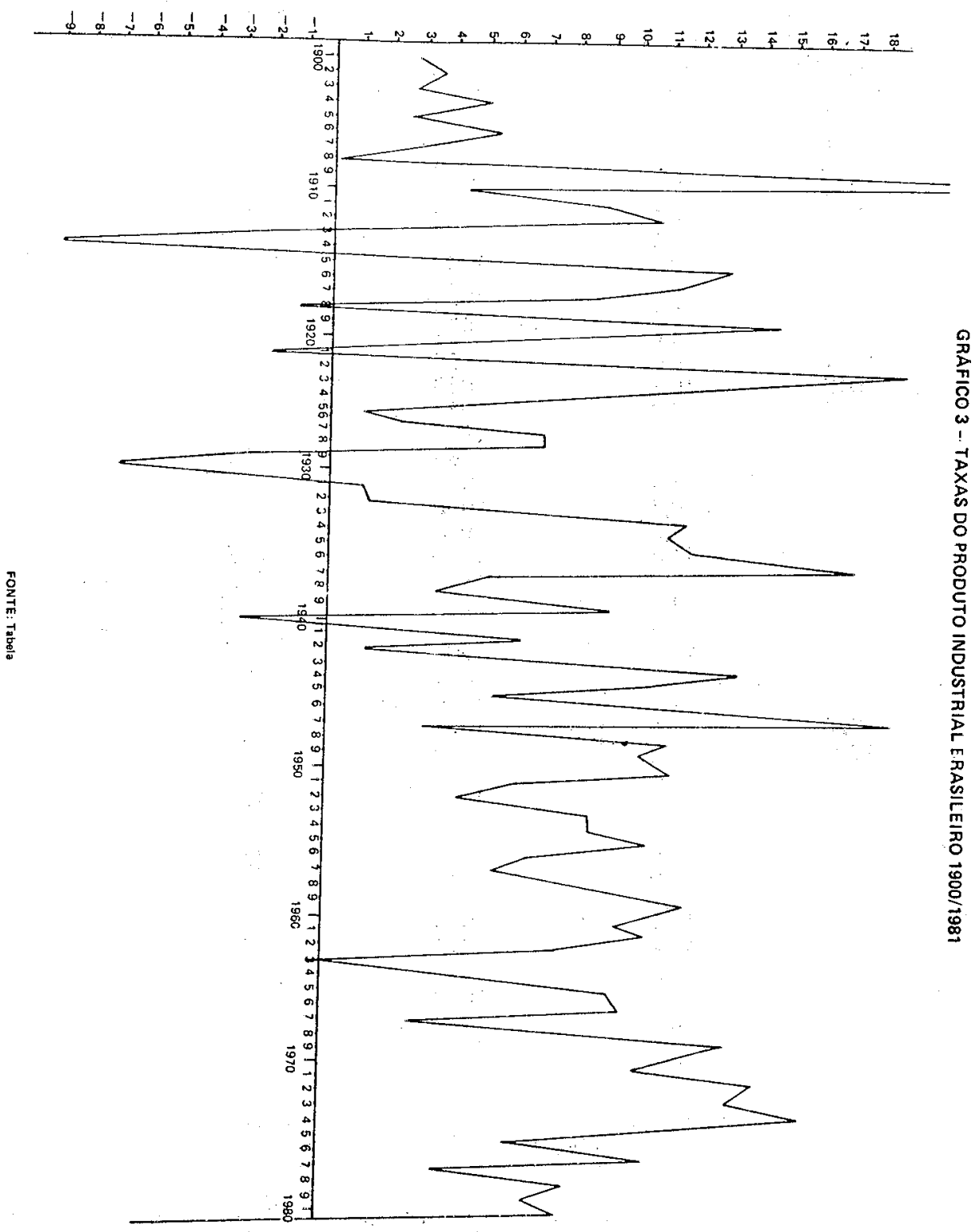

